\title{
Neural computing and applications (NCAA) special issue on best of DICTA 2019 papers
}

\author{
Ajmal Saeed Mian ${ }^{1} \cdot$ Lei Wang ${ }^{2} \cdot$ Ruiping Wang $^{3} \cdot$ Hamid Laga $^{4} \cdot$ Naveed Akhtar $^{1}$
}

Published online: 9 April 2021

(C) The Author(s), under exclusive licence to Springer-Verlag London Ltd., part of Springer Nature 2021

This Special Issue presents extended versions of the best papers presented at the International Conference on Digital Image Computing: Techniques and Applications (DICTA) which is the flagship Australian Conference on computer vision, image processing, pattern recognition, and related areas. DICTA was established in 1991 as the premier conference of the Australian Pattern Recognition Society (APRS). However, DICTA accepts submissions from researchers all over the world and attracts a significant number of international delegates each year. DICTA is technically cosponsored by the Institute of Electrical and Electronics Engineers (IEEE) and the Australian Pattern Recognition Society (APRS). DICTA 2019 was held in Perth, Western Australia, from 2 to 4 December 2019. All papers accepted and presented at DICTA 2019 are included in the IEEE Xplore digital library.

Each paper submitted to DICTA 2019 was reviewed by three experts in a double-blind review process. Based on comments from the three reviewers and assessments of the Program Chairs of the conference as well as the Guest Editors, authors of 17 papers were invited to submit extended versions of their work to this Special Issue of Neural Computing and Applications (NCAA). Each submitted paper went through a peer review process again, and 10 papers were finally accepted for publication in NCAA.

Publisher's Note Springer Nature remains neutral with regard to jurisdictional claims in published maps and institutional affiliations.
Ajmal Saeed Mian

ajmal.mian@uwa.edu.au

The University of Western Australia, Crawley, Australia

2 University of Wollongong, Wollongong, Australia

Chinese Academy of Sciences, Beijing, China

4 Murdoch University, Perth, Australia 